\title{
Effect of Halomethanes on Aflatoxin Induction in Cultures of Aspergillus parasiticus
}

\author{
By S. PASSI, ${ }^{1}$ C. FANELLI, ${ }^{2 *}$ A. A. FABBRI, ${ }^{2}$ E. FINOTTI,${ }^{2}$ G. PANFILI ${ }^{1}$ \\ AND M. NAZZARO-PORRO ${ }^{1}$ \\ ${ }^{1}$ Istituto S. Gallicano, Via S. Gallicano, 00165 Roma, Italy \\ 2 Dipartimento di Biologia vegetale, Università di Roma 'La Sapienza', \\ Largo Cristina di Svezia 24, 00165 Roma, Italy
}

(Received 18 July 1984; revised 13 November 1984)

The addition of tribromo-, tetrabromo- and chloromethanes to cultures of Aspergillus parasiticus strongly stimulated aflatoxin biosynthesis. The presence of phenobarbital in the cultures enhanced this effect. Following the addition of ${ }^{14} \mathrm{CCl}_{4}$ to a culture, after $15 \mathrm{~d}$ incubation, $8.6 \%$ of the total radioactivity was recovered from the mycelium, and $4.7 \%$ from the culture filtrate. Some $0.4 \%$ of the total radioactivity was found in microsomes, indicating their involvement in $\mathrm{CCl}_{4}$ activation and biotransformation.

\section{INTRODUCTION}

We have suggested that lipoperoxidation plays a role in inducing aflatoxin production (Passi et al., 1984). In vivo, the amount of aflatoxin formed in sunflower seeds of different ages inoculated with Aspergillus parasiticus was found to be directly related to the peroxide number in their oil content : the higher the peroxide number, the higher the aflatoxin production (Fabbri et al., 1983). In vitro, aflatoxin production was highly stimulated by the addition to cultures of $A$. parasiticus or $A$. flavus of: (1) compounds with an epoxide ring [cerulenin and tetrahydrocerulenin (Fanelli et al., 1983a), and 9,10-epoxymethylstearate and 9,10:12,13-diepoxymethylstearate (Fanelli et al., 1983b)]; (2) synthetic hydroperoxides (obtained by the reaction of lipoxygenase on linoleic acid) (Fabbri et al., 1983); (3) UV-peroxidated sitosterols and ergosterol (the main sterols of seeds and fungi respectively) (Fanelli et al., 1983c); (4) carbon tetrachloride, chloroform and other halomethanes (Fanelli et al., 1984). In the case of carbon tetrachloride we have postulated that stimulation of aflatoxin production by $A$. parasiticus might be due to the peroxidation of lipids of the endoplasmic reticulum by highly reactive radicals formed by the interaction of carbon tetrachloride with the NADPH-cytochrome P-450 system of the fungus. This system has been demonstrated in the microsomes of $A$. parasiticus (Bhatnagar et al., 1982).

In this connection we decided to study the fate of $\mathrm{CCl}_{4}$ in cultures of $\mathrm{A}$. parasiticus supplemented with ${ }^{14} \mathrm{CCl}_{4}$. In addition, dichloro-, trichloro-, tetrachloro-, bromo- and iodomethanes were tested for their effectiveness in inducing aflatoxin production.

\section{METHODS}

Fungal cultures. A strain of Aspergillus parasiticus Speare (NRRL 2999) that gave high levels of aflatoxins was used. About $10^{6}$ conidia from $15 \mathrm{~d}$ cultures grown on Czapek Dox agar medium (Difco) were incubated in $50 \mathrm{ml}$ synthetic medium (Czapek Dox broth plus $5 \mathrm{mg} \mathrm{ZnSO} \mathrm{Zn}_{4} \cdot 7 \mathrm{H}_{2} \mathrm{Ol}^{-1}$ and $1 \mathrm{mg} \mathrm{Na} 2 \mathrm{MoO}_{4} \cdot 2 \mathrm{H}_{2} \mathrm{O} \mathrm{I}^{-1}$ ) supplemented with the following. (a) 0.02 to $0.2 \%$ (w/v) tetra-, tri- and dihalomethanes purchased from Fluka: $\mathrm{CCl}_{4}$ (carbon tetrachloride), $\mathrm{CHCl}_{3}$ (chloroform), $\mathrm{CH}_{2} \mathrm{Cl}_{2}$ (dichloromethane), $\mathrm{CBr}_{4}$ (carbon tetrabromide), $\mathrm{CHBr}_{3}$ (bromoform), $\mathrm{CH}_{2} \mathrm{Br}_{2}$ (dibromomethane), $\mathrm{CI}_{4}$ (tetraiodomethane), $\mathrm{CHI}_{3}$ (iodoform), $\mathrm{CH}_{2} \mathrm{I}_{2}$ (diiodomethane), $\mathrm{BrCCl}_{3}$ (trichlorobromomethane) in the presence and absence of phenobarbital ( $\mathrm{I} \mathrm{mg} \mathrm{ml}{ }^{-1}$; Sigma). (b) $50 \mu \mathrm{Ci}^{14} \mathrm{CCl}_{4}$ (26.9 $\mathrm{mCi} \mathrm{mmol}^{-1}$; $995 \mathrm{MBq} \mathrm{mmol}^{-1}$; Amersham) plus $0 \cdot 2 \%$ unlabelled $\mathrm{CCl}_{4}$. 
Cultures were incubated, unshaken, at $30^{\circ} \mathrm{C}$ for $15 \mathrm{~d}$. Growth was estimated as dry weight of mycelium, as described by Fanelli et al. (1980). The total aflatoxins $\left(B_{1}+B_{2}+G_{1}+G_{2}\right)$ were extracted from filtered culture medium and individually analysed by HPLC as previously described (Fanelli et al., 1983a).

Lipid peroxidation. This was measured by the thiobarbituric acid test (Buege \& Aust, 1978) on microsomes of each mycelium, prepared as described below. Microsomes were extracted with $\mathrm{CHCl}_{3} / \mathrm{CH}_{3} \mathrm{OH}(2: 1$, v/v) and treated with thiobarbituric acid solution. The absorption at $535 \mathrm{~nm}$ was measured using a Beckman Acta VI spectrophotometer.

Experiments with ${ }^{14} \mathrm{CCl}_{4}$. After $15 \mathrm{~d}$ incubation in the presence of $50 \mu \mathrm{Ci}{ }^{14} \mathrm{CCl}_{4}$ plus $0.2 \%$ unlabelled $\mathrm{CCl}_{4}$, each radioactive culture of $A$. parasiticus was filtered on a sintered glass filter under vacuum. The mycelium was washed three times with saline and successively filtered; then it was dried over anhydrous $\mathrm{P}_{2} \mathrm{O}_{5}$ under vacuum and weighed. The combined filtrates of the washing were added to the culture medium filtrate and the total volume was measured.

Samples of mycelium and filtrate were extracted with $\mathrm{CHCl}_{3} / \mathrm{CH}_{3} \mathrm{OH}(2: 1, \mathrm{v} / \mathrm{v})$. After evaporation of the solvent under nitrogen, a measured sample of each extract was fractionated by TLC according to the method of Passi et al. (1981) to separate lipid fractions. The aflatoxins present in the residual $\mathrm{CHCl} / \mathrm{CH}_{3} \mathrm{OH}$ extracts were separated by HPLC on a reverse-phase column (RP 18; Merck) and individually collected.

A sample of the mycelium was homogenized in hypo-osmotic medium (10 mM-Tris/EDTA). The cellular fractions were separated by differential centrifugation: the 'heavy fraction' (which contains nuclei, plasma membrane and some non-disrupted cells) was pelleted at $800 \mathrm{~g}$ for $15 \mathrm{~min}$, the mitochondrial fraction at $7000 \mathrm{~g}$ for $20 \mathrm{~min}$, and the microsomal fraction at $100000 \mathrm{~g}$ for $60 \mathrm{~min}$.

The amounts of radioactivity present in the mycelium and filtrate, in their lipid fractions, in the aflatoxins, and in the pellets and supernatants following the different centrifugations were counted with a Beckman beta counter.

\section{RESULTS}

Table 1 shows the percentage recovery of radioactivity in a culture of $A$. parasiticus grown for $15 \mathrm{~d}$ in the presence of $50 \mu \mathrm{Ci}{ }^{14} \mathrm{CCl}_{4}$ plus $0.2 \%$ unlabelled $\mathrm{CCl}_{4}$. The intracellular localization of ${ }^{14} \mathrm{C}$ and the radioactivity present in the lipid fractions and aflatoxins of $\mathrm{CHCl}_{3} / \mathrm{CH}_{3} \mathrm{OH}$ extracts from both mycelium and culture filtrate are indicated.

Table 2 shows the growth (dry weight of mycelium) and aflatoxin production of $A$. parasiticus grown for $15 \mathrm{~d}$ at $30^{\circ} \mathrm{C}$ on synthetic medium supplemented with different halomethanes in the presence or absence of $1 \mathrm{mg}$ phenobarbital $\mathrm{ml}^{-1}$. The halomethanes, because of their high specific gravity and limited water solubility, settled at the bottom of the flasks after their addition to cultures. However, after $12 \mathrm{~d}$ incubation they had disappeared from the liquid cultures with the exception of $0.2 \%$ and $0.1 \% \mathrm{CI}_{4}$ and $\mathrm{CBr}_{4}$ and $0.2 \% \mathrm{CHI}_{3} . \mathrm{BrCCl}_{3}(0 \cdot 1 \%)$, $\mathrm{CHBr}_{3}(0.2 \%), \mathrm{CCl}_{4}(0.2 \%), \mathrm{CBr}_{4}(0.02 \%)$, in decreasing order, highly stimulated aflatoxin production; the dihalomethanes were less effective; $0.2 \%$ and $0.1 \%$ concentrations of $\mathrm{CI}_{4}$ and $\mathrm{CBr}_{4}$ were toxic, inhibiting growth. The addition of phenobarbital to cultures enhanced the potency of the above-mentioned compounds to induce aflatoxin output. Thiobarbituric acid tests on lipid extracts of microsomes were always negative. In other words, there was no apparent lipoperoxidation within the microsomes, measured as malondialdehyde production.

\section{DISCUSSION}

Our results on the fate of ${ }^{14} \mathrm{CCl}_{4}$ added to cultures of $A$. parasiticus showed that, after $15 \mathrm{~d}$ incubation, about $13 \%$ of the total radioactivity was recovered from the culture: $8.6 \%$ from mycelium and $4.7 \%$ from culture filtrate (see Table 1 ). As regards the intracellular localization of ${ }^{14} \mathrm{C}$, appreciable amounts of radioactivity were found in microsomes, indicating their possible involvement in $\mathrm{CCl}_{4}$ activation and biotransformation. About $73 \%$ of the ${ }^{14} \mathrm{C}$ found in the mycelium was recovered in $\mathrm{CHCl}_{3} / \mathrm{CH}_{3} \mathrm{OH}$ extracts, mainly localized in polar lipids (phospholipids, glycolipids, etc.) which remain at the origin of the TLC plate with the system used for the separation of lipids. Diglycerides, sterols, free fatty acids, triglycerides and sterol esters also contained ${ }^{14} \mathrm{C}$, indicating that a labelled catabolite, possibly $\left[{ }^{14} \mathrm{C}\right]$ acetyl-CoA, entered into biosynthesis of these fractions. Aflatoxins $B_{1}$ and $G_{1}$, separated on a reverse-phase HPLC column, showed appreciable levels of radioactivity, about three times higher in the filtrate than in the mycelium. 
Table 1. Recovery $(\%)$ of radioactivity in a culture of $A$. parasiticus $15 d$ after addition of ${ }^{14} \mathrm{CCl}_{4}$ plus unlabelled $\mathrm{CCl}_{4}$

Each result represents the mean of two determinations. Radioactivity is expressed as percentage of the ${ }^{14} \mathrm{CCl}_{4}$ activity added to the culture. See Methods for details of the fractionation procedures.
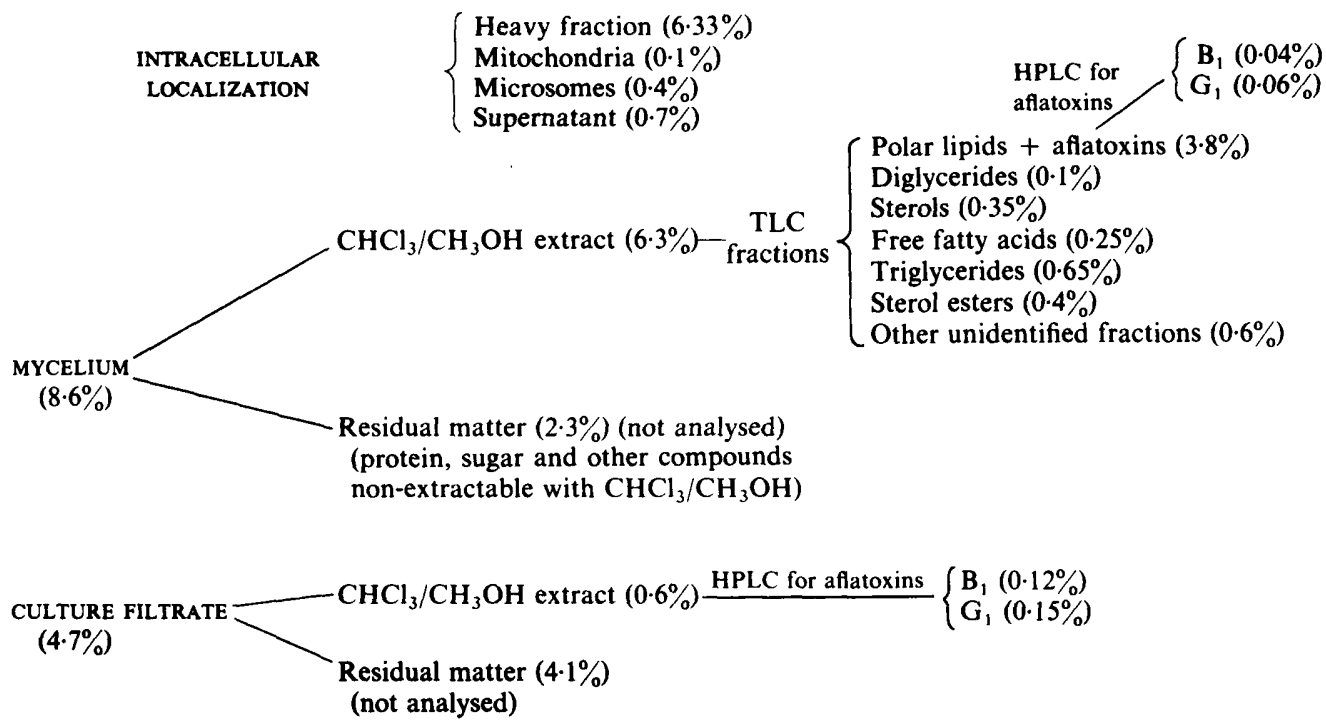

Table 2. Growth, and aflatoxin production in culture filtrates, of A. parasiticus grown for $15 d$ at $30^{\circ} \mathrm{C}$ on synthetic medium supplemented with different halomethanes in the presence or absence of phenobarbital

$\begin{array}{lcc}\begin{array}{c}\text { Halomethane } \\ \text { added to } \\ \text { medium }\end{array} & \begin{array}{c}\text { Halomethane } \\ \text { concn (\%) }\end{array} & \begin{array}{c}\text { Dry wt } \\ \text { of mycelium } \\ \text { (mg per 50 ml) }\end{array} \\ \begin{array}{l}\text { None } \\ \mathrm{CCl}_{4}\end{array} & - & 235.9 \pm 29.6 \\ \mathrm{CHCl}_{3} & 0.2 & 346.6 \pm 22.7 \\ \mathrm{CH}_{2} \mathrm{Cl}_{2} & 0.2 & 228.3 \pm 17.9 \\ \mathrm{CBr}_{4} & 0.2 & 221.9 \pm 23.7 \\ \mathrm{CHBr}_{3} & 0.02 \ddagger & 222.7 \pm 15.6 \\ \mathrm{CH}_{2} \mathrm{Br}_{2} & 0.2 & 224.2 \pm 11.0 \\ \mathrm{CI}_{4} & 0.2 & 215 \cdot 2 \pm 9 \cdot 5 \\ \mathrm{CHI}_{3} & 0.02 \ddagger & 183.5 \pm 20.1 \\ \mathrm{CH}_{2} \mathrm{I}_{2} & 0.2 & 198.8 \pm 11.7 \\ \mathrm{BrCCl}_{3} & 0.2 & 208.1 \pm 15.6 \\ \end{array}$

\begin{tabular}{|c|c|}
\hline \multicolumn{2}{|c|}{ Aflatoxin concn $(\mu \mathrm{g}$ per $50 \mathrm{ml}) \dagger$} \\
\hline $\begin{array}{l}\text { Cultures without } \\
\text { phenobarbital }\end{array}$ & $\begin{array}{l}\text { Cultures plus } \\
\text { phenobarbital }\end{array}$ \\
\hline $4 \cdot 5 \pm 3 \cdot 2$ & $10.9 \pm 6.0$ \\
\hline $118.7 \pm 16.4$ & $229.3 \pm 33.18$ \\
\hline $37.4+6.5$ & $51 \cdot 3+8.88$ \\
\hline $9.3 \pm 4.8$ & $12.2 \pm 6.7^{\circ}$ \\
\hline $92.6 \pm 20.3$ & $166.5 \pm 33.1 \S$ \\
\hline $136.5 \pm 12.8$ & $258.4 \pm 19.2 \S$ \\
\hline $20 \cdot 1 \pm 4 \cdot 3$ & $33.6 \pm 5.28$ \\
\hline $8 \cdot 6 \pm 3 \cdot 1$ & $11 \cdot 2 \pm 5.3$ \\
\hline $36 \cdot 8 \pm 4 \cdot 1$ & $52.6 \pm 3.1 \S$ \\
\hline $7.8 \pm 2.6$ & $9.9 \pm 2.9$ \\
\hline $156.4 \pm 17.2$ & $282.6 \pm 21.6 \S$ \\
\hline
\end{tabular}

* Each value represents the mean \pm SEM of ten different experiments. No significant differences in mycelial dry weight were found between cultures with and without phenobarbital.

$\dagger$ Each value represents the mean \pm SEM of five different experiments.

† Concentrations of $0 \cdot 1$ and $0 \cdot 2 \%$ of both $\mathrm{CBr}_{4}$ and $\mathrm{CI}_{4}$ were toxic for fungal growth.

$\S$ Significantly different (Student's test for unpaired data) from the values of corresponding cultures without phenobarbital $(P<0.005)$.

We did not analyse the fate of the ${ }^{14} \mathrm{CCl}_{4}$ not recovered in the cultures. However we think, by analogy with experiments with mammals, that ${ }^{14} \mathrm{CCl}_{4}$ was probably dispersed into the air during the $15 \mathrm{~d}$ incubation, either unmetabolized or biotransformed to ${ }^{14} \mathrm{CO}_{2},{ }^{14} \mathrm{CHCl}_{3}$ (the expected product of removal of hydrogen by ${ }^{14} \mathrm{CCl}_{3}$ ) or ${ }^{14} \mathrm{CCl}_{3}{ }^{14} \mathrm{CCl}_{3}$ (the expected dimerization product of ${ }^{14} \mathrm{CCl}_{3}$ radicals) (Fowler, 1969). The primary physicochemical factor in the cleavage of a halocarbon to a free radical is the potential for activation to a free radical 
species, which increases with both increasing halogenation and decreasing electronegativity of the halogen atoms. Therefore $\mathrm{CBr}_{4}$ is more likely than $\mathrm{CCl}_{4}$ to be activated to a free radical because bromine is less electronegative than chlorine, and $\mathrm{CCl}_{4}$ is more easily activated to a free radical than $\mathrm{CHCl}_{3}$ because of the greater number of halogen atoms. Our results with iodomethanes are not in line with the above theory. At $0.2 \%$ and $0.1 \%$ concentrations, both $\mathrm{CI}_{4}$ and $\mathrm{CBr}_{4}$ were extremely toxic for the fungus, but $0.02 \% \mathrm{CI}_{4}$, unlike $\mathrm{CBr}_{4}$, did not significantly enhance aflatoxin output. $\mathrm{CI}_{4}$ is practically insoluble in water but hydrolyses slowly forming iodine and $\mathrm{CHI}_{3}$. Furthermore, $0.2 \% \mathrm{CHI}_{3}$ was much less potent than $0.2 \% \mathrm{CHBr}_{3}$ in producing aflatoxin $(36.8 \pm 4.1$ against $136.5 \pm 12.8 \mu \mathrm{g}$ per $50 \mathrm{ml})$. Probably $\mathrm{CI}_{4}$ and $\mathrm{CHI}_{3}$, because of their limited water and lipid solubility, cannot act by a free radical mechanism in cultures of $A$. parasiticus.

The addition of phenobarbital $\left(1 \mathrm{mg} \mathrm{ml}^{-1}\right)$ to the cultures containing halomethanes significantly enhanced the effect of the halomethanes in inducing aflatoxin production. According to Orrenius \& Ernster (1964), phenobarbital increases synthesis of proteins and phospholipids by the endoplasmic reticulum, and the components of the NADPH-cytochrome P-450 system are all induced to stimulate the metabolism of $\mathrm{CCl}_{4}$ and other drugs. In conclusion we suggest that the induction of aflatoxin biosynthesis in $A$. parasiticus by tribromo-, tetrabromo- and chloromethanes might be due to highly reactive free radicals, and/or other toxic intermediates formed by the interaction of halomethanes with the NADPH-cytochrome P-450 system, attacking neighbouring components in the endoplasmic reticulum and causing, among other things, lipoperoxidation of unsaturated lipids.

The fact that we found no evidence of lipoperoxidation by application of the thiobarbituric test to lipid extracts from microsomes of $A$. parasiticus in the cultures supplemented with halomethanes would appear to contradict this conclusion. However, there may be a large difference between mammals and $\boldsymbol{A}$. parasiticus in the rate of metabolism of halomethanes. Following administration to mammals, halomethanes concentrate very rapidly (within a few minutes) in the liver with early striking alterations of functional activities and chemical composition of the endoplasmic reticulum (Reynolds \& Moslen, 1980).

An example of an informative chemical change is the rapid, but transient, lipoperoxidation of unsaturated fatty acids of the endoplasmic reticulum. Lipoperoxides and their breakdown products rapidly lead to cell damage and death especially if protective enzymes and antioxidants are lacking. In our cultures, halomethanes settled at the bottom of the flasks and only small amounts, depending upon their water solubility, could come into contact with the cells of $A$. parasiticus. Therefore, the process of lipoperoxidation may be very slow and difficult to evaluate. The newly formed lipoperoxides might be transformed into compounds that do not react with thiobarbituric acid, of which aflatoxin may be one. On the other hand, by-products of lipoperoxidation, such as malondialdehyde and other aldehydes might be inactivated by reacting with $-\mathrm{SH}$ and $-\mathrm{NH}_{2}$ groups of amino acids, so that reactions with thiobarbituric acid would not take place.

This study was supported for 1982, 1983 and 1984 by funds from the Ministry of Education and the Faculty of Science of Rome University 'La Sapienza'.

\section{REFERENCES}

Bhatnagar, R. K., Ahmad, S., Kohli, K. K., MUKerJi, K. G. \& Venkitasubramanian, T. A. (1982). Induction of polysubstrate monoxygenase and aflatoxin production by phenobarbitone in Aspergillus parasiticus. Biochemical and Biophysical Research Communications 104, 1287-1292.

BuEge, J. A. \& Aust, S. D. (1978). Microsomal lipid peroxidation. Methods in Enzymology 51, 301-310.

Fabbri, A. A., Fanelli, C., Panfili, G., Passi, S. \& FASElla, P. (1983). Lipoperoxidation and aflatoxin biosynthesis by Aspergillus parasiticus and A. flavus. Journal of General Microbiology 129, 3447-3452.

Fanelli, C., FabBri, A. A. \& Passi, S. (1980). Growth requirements and lipid metabolism of Aspergillus flavus. Transactions of the British Mycological Society 75, 371-375.

Fanelli, C., Fabbri, A. A., Finotti, E., Panfili, G. \& PASSI, S. $(1983 a)$. Cerulenin and tetrahydrocerulenin: stimulating factors of aflatoxin biosynthesis. Transactions of the British Mycological Society 81, 201-204.

Fanelli, C., Fabbri, A. A., Finotti, E. \& Passi, S. $(1983 b)$. Stimulation of aflatoxin biosynthesis by lipophilic epoxides. Journal of General Microbiology 129, 1721-1723.

Fanelli, C., Fabbri, A. A., Passi, S. \& Fasella, P. 
$(1983 c)$. Control mechanisms of aflatoxin production. International Mycotoxin Symposium, Sydney, August 12-15, 1983, Abst. P9.

Fanelli, C., Fabbri, A. A., Finotti, E., Fasella, P. \& PASSI, S. (1984). Free radicals and aflatoxin biosynthesis. Experientia 40, 191-193.

FOWLER, J. S. L. (1969). Carbon tetrachloride metabolism in the rabbit. British Journal of Pharmacology 37, 733-737.

OrRenius, S. \& ERnster, L. (1964). Phenobarbitalinduced synthesis of the oxidative demethylating enzymes of rat liver microsomes. Biochemical and Biophysical Research Communications 16, 60-64.
Passi, S., Rothschild-Boros, M. C., Fasella, P., Nazzaro-Porro, M. \& Whitehouse, D. (1981). An application of high performance liquid chromatography to analysis of lipids in archeological samples. Journal of Lipid Research 22, 778-784.

Passi, S., Nazzaro-Porro, M., Fanelli, C., Fabbri, A. A. \& FASElla, P. (1984). Role of lipoperoxidation in aflatoxin production. Applied Microbiology and Biotechnology 19, 186-190.

REYNOLDS, E. S. \& MosLEN, M. T. (1980). Free radical damage in liver. In Free Radicals in Biology, vol. IV, pp. 49-94. Edited by A. A. Pryor. New York: Academic Press. 